\title{
Behandling av nøytropen enterokolitt
}

\author{
Sammendrag \\ Bakgrunn. Nøytropen enterokolitt er en \\ livstruende komplikasjon som mest \\ forekommer ved kjemoterapi for akutt \\ leukemi. Vår erfaring med diagnostikk \\ og behandling av slike pasienter pre- \\ senteres.
}

Materiale og metode. Ved en retrospektiv gjennomgang av journaler fra perioden 2000-08 registrerte vi pasienter behandlet for nøytropen enterokolitt ved Oslo universitetssykehus, Ullevål.

Resultater. 16 pasienter med median alder 33 år var blitt behandlet for nøytropen enterokolitt. De hadde fått induksjonsbehandling for akutt myelogen ( $n=9$ ) eller lymfatisk ( $n=4$ ) leukemi, myelomatose eller lymfom ( $\mathrm{n}=3$ ). Median fem dager etter start av induksjonsbehandling fikk pasientene aplasi. Alle fikk initialt konservativ behandling med bredspektrede antibiotika, væske- og elektrolyttilførsel. $\mathrm{Ni}$ overlevde etter konservativ behandling alene. Fire måtte opereres. Disse hadde lengst aplasiperiode (median 31 dagerl. Tre døde. Disse fikk kun konservativ behandling og de fikk raskere aplasi, som inntrådte etter median to dager. Disse pasientene hadde også størst antall fortykkede tarmsegmenter (median ni).

Fortolkning. Nøytropen enterokolitt er en heterogen tilstand, og behandlingen er hovedsakelig konservativ. Kirurgisk intervensjon er nødvendig hos pasienter med fri luft intraabdominalt, ileus og intraktabel tarmblødning. Kort tid til aplasi og mange affiserte tarmsegmenter synes å forverre prognosen.
Ghous Gondal*

ghousgondal@hotmail.com

Egil Johnson

Gastrokirurgisk avdeling

Vemund Paulsen

Gastromedisinsk avdeling

Banitalebi Hasan

Radiologisk avdeling

Oslo universitetssykehus, Ullevål

0407 Oslo

* Nåværende adresse:

Gastrokirurgisk avdeling

Sykehuset Østfold

Postboks 60

1603 Fredrikstad

Nøytropen enterokolitt er en alvorlig komplikasjon til kjemoterapi. Tilstanden er rapportert hos $6 \%$ av dem med maligne blodsykdommer (1), men kan også forekomme etter organtransplantasjon og kjemoterapi for maligne solide svulster. Nøytropen enterokolitt kan ha forskjellig alvorlighetsgrad fra milde gastrointestinale symptomer til peritonitt og sepsis. Det eksisterer ingen internasjonalt aksepterte diagnostiske kriterier for tilstanden. CT og ultralyd er viktige undersøkelser for å diagnostisere og finne utbredelsen (2-4). Graden av veggfortykkelse i tarmen og aplasitidens varighet har vært foreslått som mulige prognostiske faktorer (2-4). Ved tidlig intensiv behandling med bredspektrede antibiotika kan mortaliteten reduseres (5). Kirurgi må overveies ved tegn på peritonitt, tarmperforasjon og intraktabel blødning.

Vi presenterer her våre erfaringer med behandling av 16 pasienter med nøytropen enterokolitt ved Oslo universitetssykehus, Ullevål.

\section{Materiale og metode}

Siden det ikke finnes noen diagnosekode for nøytropen enterokolitt, ble koder for ondartede svulster i lymfoid vev, hematopoetisk vev eller beslektet vev (ICD-kode C81C91), ikke-infeksiøse enteritter og kolitter (ICD-kode K50-K52) samt tilhørende operasjonskoder (ICD-kode JAH og JF) benyttet i søket etter aktuelle pasienter.

For disse måtte det være en kombinasjon av minst to diagnosekoder for at de skulle bli inkludert. Det foreligger aplasi ved nøytrofile granulocytter $<0,5 \cdot 10^{9} / 1$ etter start av induksjonsbehandlingen med kjemoterapi. Vi definerte nøytropen enterokolitt som abdominalsmerter med eller uten blodig diaré og enterokolittforandringer med fortykkelse av tarmveggen påvist ved CT abdomen. Ved diaré ble avføringsprøve undersøkt for Clostridium difficile-toksin og patogene tarmbakterier. CT abdomen ble for alle pasienter gjennomført $i$ arteriovenøs fase med snittykkelse $2 \mathrm{~mm}$. Pasientene ble gitt $30 \mathrm{ml}$ peroral kontrast (natriummetylglukamin $370 \mathrm{mg} / \mathrm{ml}$ (Gastrografin)) oppløst i vann til sluttvolum 11 en time før undersøkelsen.

Pasientene fikk væske- og elektrolyttsubstitusjon og blodprodukter ved persisterende anemi og koagulopati. Avhengig av allmenntilstand ble de ernært parenteralt, enteralt og/eller peroralt. Hvis det var feber eller frostanfall, ble det tatt blodkultur og iverksatt behandling med bredspektrede antibiotika. Ved ileus eller fri luft intraabdominalt ble pasientene operert.

Antall dager med aplasi og antall dager fra aplasi oppsto til pasienten fikk gastrointestinale symptomer (smerter, kvalme, oppkast, diaré og blod per rectum) ble registrert. Alle CT-bilder ble retrospektivt gransket på nytt i forbindelse med denne gjennomgangen. Ved CT abdomen ble maksimal veggfortykkelse av tynn- og tykktarm målt og antall affiserte tarmsegmenter angitt. Veggfortykkelse i tarmen på minst 4 $\mathrm{mm}$ ble oppfattet som patologisk. Lengden på sykehusoppholdet inkluderte alle liggedøgn i sengepost, postoperativ avdeling og intensivavdeling. Mortaliteten ble definert som dødsfall på grunn av nøytropen enterokolitt under aktuelle sykehusopphold.

\section{Resultater}

16 pasienter (åtte kvinner) med median alder 33 år ble behandlet for kjemoterapiindusert

\section{Hovedbudskap}

- Nøytropen enterokolitt er en alvorlig komplikasjon til kjemoterapi, vanligst ved akutte leukemier

- Behandlingen er hovedsakelig konservativ

- Kirurgisk intervensjon er nødvendig ved fri intrabdominal luft, ileus og intraktabel tarmblødning

- Kort tid til aplasi og mange affiserte tarmsegmenter synes å indikere dårligere prognose 
Tabell 1 Forskjellige faktorer hos pasienter med nøytropen enterokolitt inndelt etter type behandling, overlevelse og død. For å ivareta anonymiteten er pasientenes alder utelatt fra tabellen

\begin{tabular}{|c|c|c|c|c|c|c|c|c|}
\hline \multirow[b]{2}{*}{ Faktorer } & \multicolumn{2}{|c|}{$\begin{array}{l}\text { Alle pasienter } \\
\qquad(\mathrm{n}=16)\end{array}$} & \multicolumn{2}{|c|}{$\begin{array}{l}\text { Overlevde etter kon- } \\
\text { servativ behandling } \\
\qquad(\mathrm{n}=9)\end{array}$} & \multicolumn{2}{|c|}{$\begin{array}{l}\text { Overlevde etter } \\
\text { konservativ og kirur- } \\
\text { gisk behandling } \\
(n=4)\end{array}$} & \multicolumn{2}{|c|}{$\begin{array}{l}\text { Døde etter konser- } \\
\text { vativ behandling } \\
\qquad(\mathrm{n}=3)\end{array}$} \\
\hline & Median & Spredning & Median & Spredning & Median & Spredning & Median & Spredning \\
\hline Antall dager fra induksjonsbehandling til aplasi & 5 & $1-13$ & 5 & $3-10$ & 10 & $4-13$ & 2 & $1-7$ \\
\hline Antall dager med aplasi & 19 & $10-74$ & 19 & $11-46$ & 31 & $14-74$ & 17 & $15-56$ \\
\hline Dager fra aplasi til første abdominal symptomer & 8 & $1-50$ & 4 & $1-13$ & 10 & $7-50$ & 8 & $1-15$ \\
\hline Dager fra aplasi til CT abdomen-undersøkelse & 10 & $1-50$ & 4 & $1-13$ & 23 & $11-50$ & 13 & $10-16$ \\
\hline $\begin{array}{l}\text { Antall fortykkede tarmsegmenter med entero- } \\
\text { kolittforandringer }\end{array}$ & 5 & $1-9$ & 3 & $1-9$ & 4 & $2-9$ & 9 & $7-9$ \\
\hline $\begin{array}{l}\text { Største CT-verifiserte fortykkelse av tarmsegment } \\
\text { (mm) }\end{array}$ & 11 & $4-20$ & 11 & $4-20$ & 10,5 & $5-19$ & $15^{1}$ & 1 \\
\hline
\end{tabular}

Største fortykkelse av tarmsegment ble målt hos kun én pasient, siden de øvrige to pasienter hadde pneumatosis intestinalis

nøytropen enterokolitt i perioden januar 2000-mai 2008. Ni hadde akutt myelogen leukemi, fire akutt lymfatisk leukemi, tre myelomatose eller lymfom.

Median fem dager etter induksjonsbehandlingen fikk pasientene aplasi (tab 1). Pasientene hadde median 19 dager med aplasi. Abdominalsymptomer oppsto median åtte dager etter første aplasidag. Alle fikk initialt konservativ behandling med bredspektrede antibiotika, væske- og elektrolyttilførsel. 13 pasienter overlevde, hvorav ni fikk kun konservativ behandling, mens fire måtte opereres. Tre konservativt behandlede pasienter døde av multiorgansvikt. Hos disse gikk det kortere tid fra start av induksjonsbehandling til utvikling av aplasi (to dager) enn hos dem

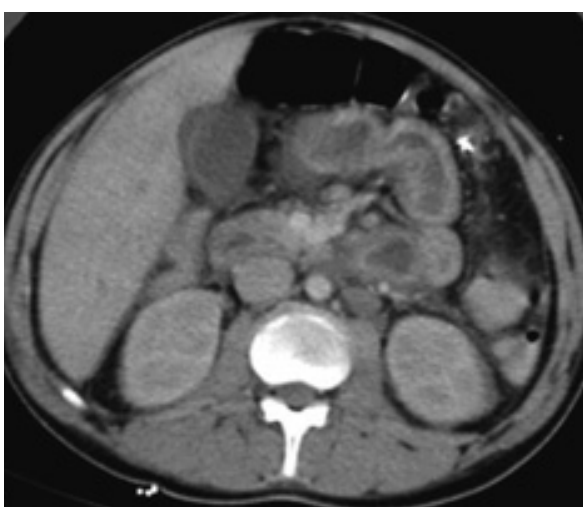

Figur 1 CT abdomen viser betydelig veggfortykkelse i tynntarmen $(8-9 \mathrm{~mm}$ )

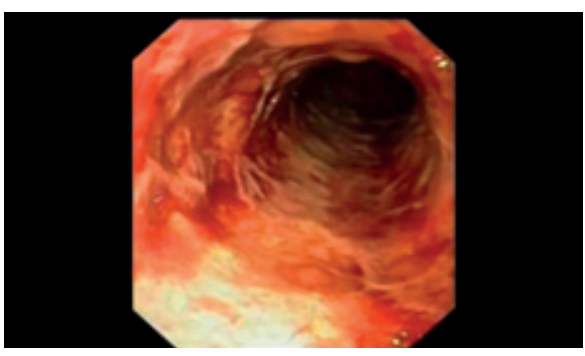

Figur 2 Endoskopisk bilde fra colon descendens som viser lettblødende slimhinne med omfattende ulcerasjoner som overlevde operativ behandling (ti dager) eller utelukkende konservativ behandling (fem dager). Disse pasientene hadde også størst antall fortykkede tarmsegmenter (median ni). De opererte hadde lengre aplasitid enn de uopererte.

Fire pasienter ble operert, tre pga. fri luft intraabdominalt ved CT. Hos disse tre fant man tarmperforasjon. De opererte hadde lengst aplasiperiode (median 31 dager). Behandlingen var reseksjon og fremlegging av toløpet eller enløpet ileostomi.

Pasientene var innlagt i sykehuset i median 55 dager (23-119 dager), derav ni dager (2-69 dager) i postoperativ avdeling og intensivavdeling.

\section{Diskusjon}

Nøytropen enterokolitt er en alvorlig tilstand, med en mortalitet på $8-40 \%(2,6,7)$. Den kan progrediere raskt fra milde magesmerter og subfebrilia til livstruende septisk sjokk. Klinisk undersøkelse er av begrenset verdi og må suppleres med CT-undersøkelse (fig 1) eller ultralyd abdomen, som gir best diagnostisk resultat og utelukker andre patologiske tilstander (2-4).

I vårt materiale fikk de som døde aplasi kort tid etter induksjonsbehandling, og de hadde mange fortykkede tarmsegmenter (tab 1). Dette er funn som ikke har vært rapportert tidligere.

Lang aplasitid ble påvist hos dem som trengte kirurgisk behandling. Kortvarig aplasi begrenser inflammasjonen til tarmmucosa (mukositt), langvarig aplasi forårsaker kontinuerlig bakteriell invasjon av tarmveggen, med ulcerasjoner (fig 2), nekrose og perforasjon. Disse funnene er i samsvar med observasjoner gjort av Wade \& Nava (8). Imidlertid forekommer økt fortykkelse av tarmveggen også ved kolitt utløst av Clostridium difficile, transplantat-mot-vert-sykdom, cytomegalovirusinfeksjon og tarmiskemi (4). Derfor må disse tilstandene utelukkes hvis radiologiske funn skal ligge til grunn for diagnosen nøytropen enterokolitt.
Tarmens veggtykkelse øker med varigheten av abdominale symptomer $(2,3)$. Cartoni og medarbeidere rapporterte $60 \%$ mortalitet hos pasienter med tarmveggsfortykkelse $>10 \mathrm{~mm}(2)$.

Behandlingen av nøytropen enterokolitt må vurderes individuelt ut fra kliniske og røntgenologiske funn. Generelt anbefales initialt konservativ behandling (5, 9-11) med bredspektrede antibiotika, væske- og elektrolyttilførsel og blodprodukter, og enteral ernæring tilstrebes. Derimot er kirurgi nødvendig hos pasienter med fri luft intraabdominalt eller alvorlig gastrointestinal blødning (9-11). Ved kirurgi skal nekrotiske og perforerte tarmsegmenter reseceres. Primære anastomoser bør unngås, særlig ved leukopeni og pågående kjemoterapi, hvor risikoen for anastomoselekkasje er stor (9, 10). I vårt materiale overlevde fire pasienter tarmreseksjon med fremlegging av stomi. Slik behandling er forenlig med aksepterte kriterier for kirurgi ved nøytropen enterokolitt $(11,12)$ og er vist å kunne bedre progno$\operatorname{sen}(5)$.

Ved nøytropen enterokolitt er konservativ behandling hjørnesteinen, men kirurgi er nødvendig ved irreversible skader på tarmen og alvorlig blødning. Kort tid til aplasi etter induksjonsbehandling og patologisk fortykkelse av mange tarmsegmenter synes å innebære dårligere prognose.

Oppgitte interessekonflikter: Ingen

\section{Litteratur}

1. Gorschluter M, Mey U, Strehl J et al. Neutropenic enterocolitis in adults: systematic analysis of evidence quality. Eur J Haematol 2005; 75: 1-13.

2. Cartoni C, Dragoni F, Micozzi A et al. Neutropenic enterocolitis in patients with acute leukemia: prognostic significance of bowel wall thickening detected by ultrasonography. J Clin Oncol 2001; 19: $756-61$

3. Dietrich CF, Hermann S, Klein S et al. Sonographic signs of neutropenic enterocolitis. World J Gastroenterol 2006; 12: 1397-402. 
4. Kirkpatrick ID, Greenberg HM. Gastrointestinal complications in the neutropenic patient: characterization with abdominal CT. Radiology 2003; 226: $668-74$.

5. Alt B, Glass NR, Sollinger H. Neutropenic enterocolitis in adults. Review of the literature and assessment of surgical intervention. Am J Surg 1985; 149: 405-8.

6. Sloas MM, Flynn PM, Kaste SC et al. Typhilitis in children with cancer: a 30 -years experience. Clin children with cancer: a 30-year
Infect Dis 1993; 17: 484-90.

7. Hogan WJ, Letendre L, Litzow MR et al. Neutropenic colitis after treatment of acute mylogenous leukemia with indraubicin and cytosine arabinoside. Mayo Clin Proc 2002; 77: 760-2.

8. Wade DS, Nava HR. Neutropenic enterocolitis. Clinical diagnosis and treatment. Cancer 1992; 69: $17-23$.

9. Villar HV, Warneke JA, Peck MD et al. Role of surgical treatment in the management of complications of the gastrointestinal tract in patients with leukemia. Surg Gynecol Obstet 1987; 165: 217-22.

10. Glenn J, Funkhouser WK, Schneider PS. Acute illnesses necessitating urgent abdominal surgery in neutropenic cancer patients: description of 14 cases and review of the literature. Surgery 1989; 105: 778-89.

11. Moir CR, Scudamore CH, Benny WB. Typhlitis: selective surgical management. Am J Surg 1986; 151: 563-6.

12. Mower WJ, Hawkins JA, Nelson EW. Neutropenic enterocolitis in adults with acute leukemia. Arch Surg 1986; 121: $571-4$

Manuskriptet ble mottatt 22.7. 2008 og godkjent

10.9. 2009. Medisinsk redaktør Odd Terje Brustugun. 